\title{
CANOPY ARTHROPOD STUDIES IN SRI LANKA: IMPLICATIONS FOR CONSERVATION
}

\author{
DEVAKA K. WEERAKOON \\ Department of Zoology, University of Colombo, Sri Lanka
}

Proceedings of the South and Central Asian MAB Meeting of Experts on Environmental Conservation, Management and Research, Hikkaduwa, Sri Lanka 15-18 October 2002

\section{Background}

Tropical forests are among the planet's most productive and biologically diverse habitats. Out of the described 1.8 million species, more than half are found in the tropical forests. However, most of the species found in the tropical forests are yet to be described. According to a recent estimate, the taxonomy of more than 90 per cent of the arthropod species found in tropical rain forests is not known at present. ${ }^{10} \mathrm{Of}$ these, the canopy arthropods were the most understudied group, until Martin ${ }^{5}$ developed the canopy fogging technique to study canopy arthropods. In recent times, canopy studies have revealed a wealth of information about the arthropod diversity that can be seen in the forest canopy. ${ }^{6,8,9}$

These studies have revealed an unexpected richness of arthropods in the forest canopy. For instance, Stork ${ }^{7}$ sampled 19 trees of Luehea seemannii, a medium-sized open canopy tree found in semi-evergreen forests, which yielded over 955 species of beetles, excluding weevils. Another canopy study done in Venezuela yielded 972 species of beetles from just six rain forest trees. ${ }^{1}$ These discoveries have provided the basis for current estimates of the number of all living species on earth. ${ }^{2,8}$

Thus the forest canopy will be the new frontier in biodiversity research. However, the canopy arthropod diversity of Sri Lanka remains relatively unknown except for the studies conducted by Gunatilleke \& Gunatilleke $e^{4}$ on the role of insects in the pollination of trees that form the canopy of the Sinharaja rain forest. Therefore, the objective of this study was to investigate the canopy arthropod diversity in Sri Lanka. Two studies were conducted to determine the canopy arthropod diversity in two study sites. The first study was conducted in 1999 at a site near the Peak Wilderness Wildlife Sanctuary, one of the high biodiversity areas in Sri Lanka with the objective of developing the necessary study techniques as well as to get an approximate idea about the diversity that exists in the forest canopy. ${ }^{3}$ This was followed by a detailed study in 2000 in the Knuckles floristic region, another high biodiversity area, to determine the diversity, abundance, and species richness of arthropods found in the forest canopy and to determine the spatial distribution patterns and temporal variations in the canopy arthropod composition. 


\section{Methodology}

Study site 1: The first study site was selected in the wet zone in the Kuru River Basin close to the Peak Wilderness Wildlife Sanctuary. The study site was located at $6^{\circ} 50^{\prime} \mathrm{NL}$ and $80^{\circ} 25^{\prime} \mathrm{EL}$. The main floristic type found in the area can be classified as Tropical wet evergreen forest formation.

Study site 2: The second study site was selected in the wet zone close to the Knuckles Conservation Forest. The study site lies near the Coberts' Gap area, which is situated at $7^{\circ} 22^{\prime}$ NL and $80^{\circ} 51^{\prime}$ EL. The main floristic type found in the area can be classified as Tropical wet submontane evergreen forest. The canopy layer of this forest is formed by Actinodaphne stenophylla, Calophyllum walkeri, Canthium montanum, Cinnamomum ovalifolium, Elaeocarpus amoenus, Litsea gardneri, L. ovalifolia, Schefflera racemosa, Syzygium gardneri, S. umbrosum, and S. zeylanicum, and generally reaches a height of about $20-25 \mathrm{~m}$.

Selection of trees for sampling: In the first study site, a single tree of the common canopy species Campnosperma zeylanica (Anacardiaceae) was chosen for the study. In the second study site, two species, Syzygium umbrosum and $S$. spatulatum were selected for the study. These two species were selected as they were found to be the commonest species in the study site. Furthermore, $S$. umbrosum is found in areas sheltered by the wind and therefore grows up to about $20 \mathrm{~m}$, while S. spatulatum is found in areas subjected to high wind and therefore does not grow more than $1.5 \mathrm{~m}$.

Sampling strategy: In the first study site, a single sampling session was carried out where an insecticide fog was applied to the canopy using a swing fog as described in detail below. In the second site, sampling was carried out by season to determine seasonal variations in arthropod assemblages. Three seasons were chosen namely, flowering, fruiting and new leaf flush. During each sampling season, three trees each from the two species were sampled. However, as this is an ongoing study, only data from the leaf flush sampling session will be presented in this paper. Each sampling session lasts four days. During the first three days the canopy arthropods were collected with the aid of traps (Malaise and water pan traps) and on the fourth day the canopy was fogged using a knock down insecticide.

Canopy fogging: Ten $0.5 \mathrm{~m}^{2}$ funnel shaped trays were suspended by ropes at breast height within the crown spread of the tree that was to be sampled (Fig 1a and 1b). 2 liters of the insecticide "Baythroid" (0.001 ppt dissolved in water) was applied to the canopy using an "Sn50 Swing fogger". The fogging machine was hoisted to the tree crown with the aid of a rope and pulley system to ensure that only the canopy was exposed to the fog. Fog was released over a 10 minute period into the canopy region while rotating the fogging machine to ensure that all parts of the tree crown was exposed to the fog in a uniform manner. Fogging of each tree crown was carried 
out between 7.00 a.m. to 9.30 a.m. in dry and zero wind conditions. Two hours after fogging, arthropods were collected.

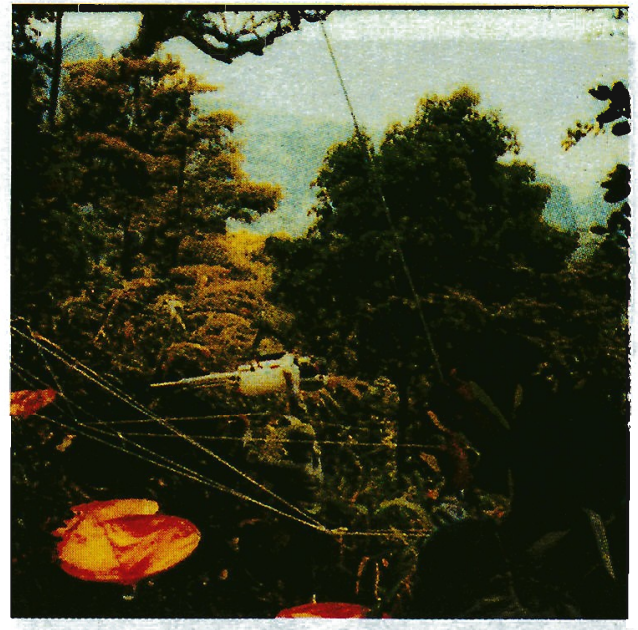

Figure 1a: Suspension of the Cones at Breast Height Underneath the Canopy for Specimen Collection.

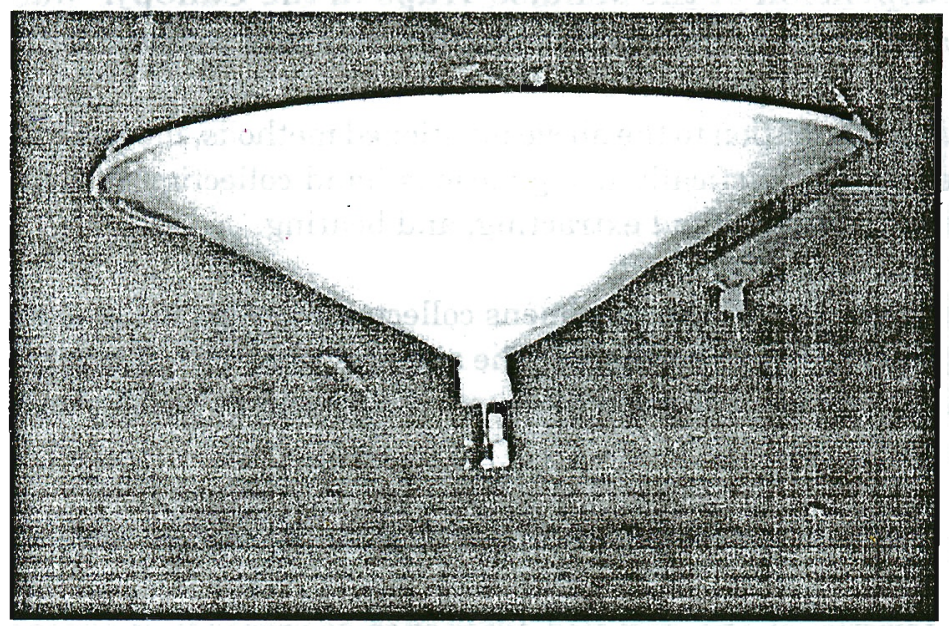

Figure 1b: Detailed view of a cone

Malaise Trap: A malaise trap was placed in the canopy with the aid of a pulley and ropes. The trapping was conducted for three consecutive days. On each day, the trap was inspected twice, at 6:00 a.m. and 6:00 p.m., and the insects captured were collected (Figure 2). 
Water pan traps: Four yellow trays of $30 \mathrm{~cm} \times 15 \mathrm{~cm} \times 5 \mathrm{~cm}$ were attached to the base of each malaise trap. The trays were filled with soap water. When each malaise trap was inspected, all insects collected in the water pan trap were also collected.

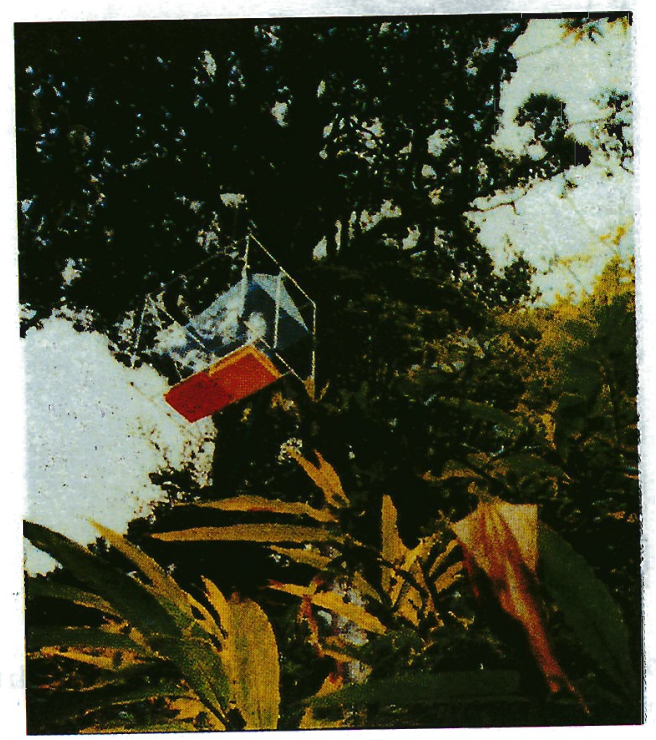

Figure 2: Suspension of the Malaise Traps in the Canopy. Water pan traps can be seen at the base of the Malaise trap (Orange and Yellow colour)

Hand collecting: In addition to the above mentioned methods, insects from the canopy were collected opportunistically using various hand collection techniques such as aspiration, hand netting, hand extracting, and beating.

Curation and analysis: All the specimens collected were placed in separate sample bottles and preserved in $70 \%$ ethanol. The samples were sorted into morphospecies in the laboratory and identification was carried out as far as possible using published taxonomic keys (Figure 3).

In addition, the following vegetation and ecological characters were also recorded.

- Characteristics of the sampled trees such as presence or absence of flowers, presence or absence of fruits, diameter at breast height $(\mathrm{cm})$, maximum and minimum width of the crown $(\mathrm{m})$, height of the tree $(\mathrm{m})$, presence or absence of old and new leaves, structure of the bark, presence or absence of dead woods, number and composition of epiphytes.

- Basic weather data such as temperature and humidity. 


\section{Results:}

Sampling of Campnosperma zeylanica: A total of 228 individuals belonging to 18 orders were collected. These individuals were separated into 111 morphospecies. Of the morphospecies recorded, the highest number belonged to the order Diptera (33) followed by the order Hymenoptera (22), the order Araneida (14), and the order Coleoptera (12). The rest of the orders was represented by 5 or less morphospecies (Figure 3).

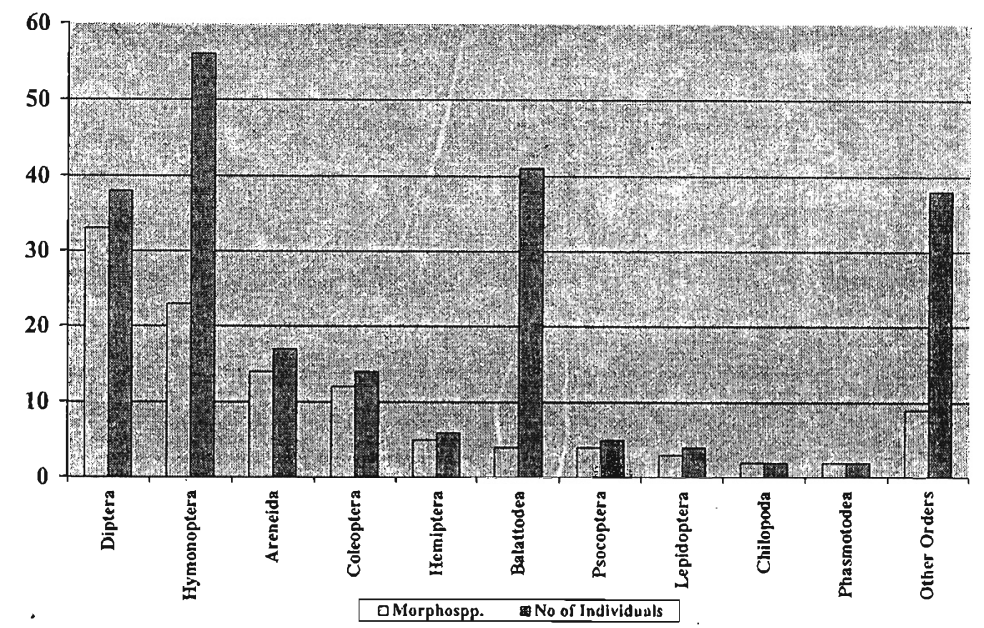

Figure 3: Number of Individuals and Morphospecies Recorded in Various Arthropod Orders from Campnosperma zeylanica.

Sampling of Syzigium umbrosum: A total of 1,444 individuals belonging to 19 orders were collected from three trees during the leaf flush stage. Of the arthropods recorded, the highest number belonged to the order Psocoptera (343) followed by the order Collembola (337), the order Diptera (256), the order Hymenoptera (250), the order Coleoptera (62), the order Thysanoptera (41), the order Homoptera (28) and the order Heteroptera (13). The rest of the orders was represented by 10 or less individuals (Figure 4).

Sampling of Syzigium spatulatum: A total of 150 individuals belonging to 10 orders were collected from three trees during the leaf flush stage. Of the arthropods recorded, the highest number belonged to the order Diptera (45) followed by the order Hymenoptera (41), the order Collembola (33), the order Araneida (12), and the order Homoptera (10). The rest of the orders were represented by 10 or less individuals (Figure 5). 


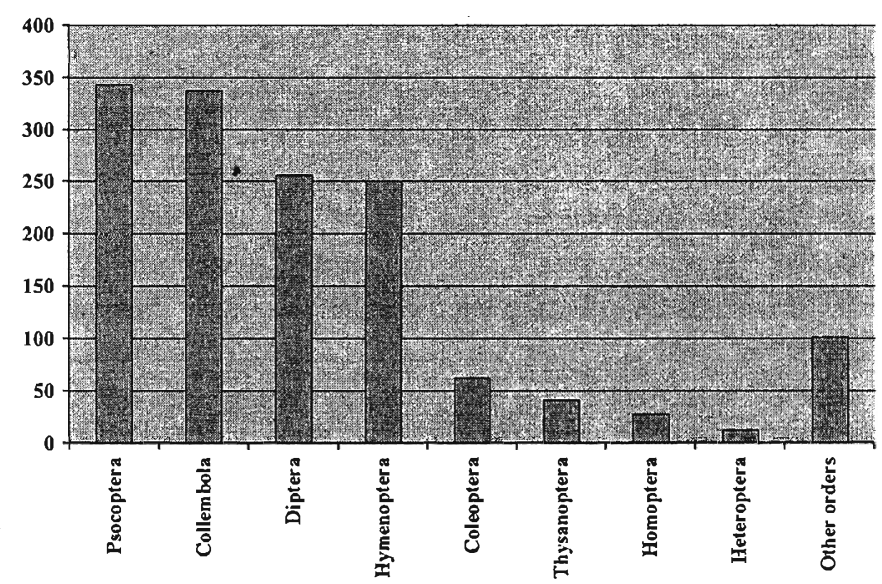

Figure 4: Number of Individuals Recorded in Various Arthropod Orders from Syzigium umbrosum During the Leaf Flush Stage $(n=3)$

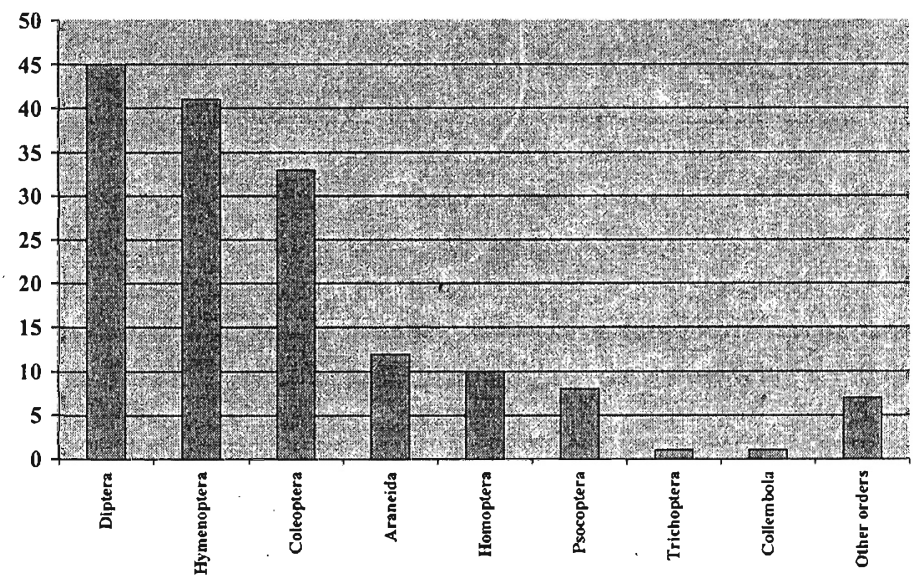

Figure 5: Number of Individuals Recorded in Various Arthropod Orders from Syzigium spatulatum During the Leaf Flush Stage (n = 3)

\section{Discussion}

The information available on animal diversity in the world is largely restricted to vertebrate species. Even though arthropods make up more than $60 \%$ of the total animal diversity in the world, very little emphasis has been given to the study of arthropod diversity. In Sri Lanka too, the same conditions prevail. Only a few groups of arthropods have been well studied, while the majority of arthropods are largely neglected. However, to make a realistic estimation of the biodiversity of Sri Lanka, a better understanding of this group is required. Furthermore, most of the faunal studies in Sri Lanka are restricted to the forest floor. In recent times, studies done in other countries have revealed that the forest canopy supports a large variety of 
species. With this in mind, a study was initiated at two sites in the wet zone of Sri Lanka to estimate the canopy arthropod diversity.

The canopy of three wet zone forest species, Campnosperma zeylanica, Syzigium umbrosum and Syzigium spatulatum were sampled using the single tree canopy fogging technique and number of traps. Although these investigations are still at a very preliminary stage, the results demonstrate that the forest canopy of the wet zone forests support a large number of arthropod species indicating that the canopy arthropod diversity in Sri Lanka is likely to be very high. The data also show that the species assemblage varies from tree species to tree species.

These results are restricted to three species and two major floristic zones. Therefore, even though these studies indicate that the trees forming the canopy of wet zone forest support a high arthropod diversity, much more detailed studies are needed to get an accurate estimate of the true canopy arthropod diversity that exists in Sri Lanka. Thus, an attempt should be made to develop a longterm study of the forest canopy to systematically inventorize the canopy arthropod diversity. The study should be extended to other dominant forest species as well as other floristic regions. The information gathered from such studies would allow for a more accurate estimation of Sri Lanka's true biodiversity.

One of the biggest constraints faced during this study was the lack of taxonomists for arthropods in Sri Lanka. Therefore, if Sri Lanka is to undertake detailed canopy arthropod studies, this deficiency must also be addressed. As such, training arthropod taxonomists should be given a high national priority. Furthermore, links and collaboration with experts and institutions in other countries must also be established.

\section{References}

1 Davies J. G., Stork. N.E., Brendell M.J.D. \& Hine S. J. (1997) Beetle species diversity and faunal similarity in Venezuelan rainforest tree canopies. In: Canopy Arthropods Stork N.E.; Adis J. \& Didham R.K. (Eds.). Chapman \& Hall, London. 85-103.

2 Guilbert E. (1997). Arthropod biodiversity in the canopy of New Caledonian forests. In: Canopy Arthropods Stork N,E.; Adis J. \& Didham R.K. (Eds.) Chapman \& Hall, London. 265-277.

3 Goonatilake W.L.D.P.T.S. de A.\& Weerakoon D.K. (2000). A Preliminary study of arthropod diversity in the canopy of Campnosperma zeylanica Thw, at Peak Wilderness Sanctuary. Proceedings of the $6^{\text {th }}$ Annual Forestry and Environment Symposium. Kandy, Sri Lanka. p. 34. 
4. Gunatilleke S. \& Gunatilleke N. (2000). Pollination secrets of canopy giants in the Sinharaja Forest, Sri Lanka. Sri Lanka Nature. 3 (4) : 52-64.

5 Martin J.L. (1966). The insect ecology of red pine plantations in central Ontario - IV. The crown fauna. Canadian Entomologist 98: 10-27.

6 Russell-Smith A. \& Stork N.E. (1995). Composition of Spider communities in the canopies of rainforest trees in Borneo. Journal of Tropical Ecology. 11: 223-235.

7 Stork N.E. (1997). Measuring global biodiversity and its decline. In: Biodiversity II, Understanding and protecting Our Biological Resources. Reaka-kudla M. L.; Wilson D. E. \& Wilson E.O. (Eds.) 41-68.

8 Stork N. E., Adis J., \& Didham R. K. (Eds.) (1997a). Canopy Arthropods. Chapman \& Hall, London. 565pp.

9 Stork N.E., Didham R.K. \& Adis J. (1997b). Canopy Arthropod studies for the future. In: Canopy Arthropods N.E. Stork; J. Adis \& R.K. Didham (Eds.) Canopy \& Hall, London. 551-561.

10 Wright J. (Ed.). (1992). Accessing the Canopy; Assessment of biological diversity and microclimate of the tropical forest canopy, Phase 01. UNEP. $88 \mathrm{p}$. 